supposed, a monophyletic group derived from annelids but a polyphyletic assemblage the ancestry of which is obscure. The immense problem of locating ancestral forms is evident when one considers the diversity of arthropods, some displaying considerable complexity, and often of problematic affinities, already differentiated by Cambrian times. The concept of a polyphyletic origin, already supported by embryological studies, implies a great deal of convergence, but will surely win the day.

Manton goes further than this and believes that the hexapods do not represent a monophyletic assemblage but probably have a fivefold origin, the Collembola, Protura, Diplura, Thysanura and Pterygota being independently evolved from multilegged ancestors with a head fundamentally different from that of myriapods. Such a view will meet with resistance from some entomologists; and already, for example, Kristensen ( $Z$. Zool. Syst. Evolut.-Forsch. 13, 1-44; 1975) has disagreed with such a conclusion. He also persists in using the term Entognatha as a taxonomic unit, which surely weakens his case. Manton believes that entognathy should be used as a purely descriptive term of no phyletic significance. That it could have arisen independently in different groups of hexapods is suggested by the fact that it has done so in copepods and isopods, both groups of which crustaceans display varying degrees of its acquisition according to functional demands.

Kristensen views hexapod evolution from within what, whatever its merits, some would regard as the straight-jacket of Hennigian phylogenetic systematics, whereas Manton takes a broader view. It would have been pleasing, however, if some of his well reasoned arguments concerning the possible existence of stages that Manton believes to have been functionally impossible had been specifically considered. Presumably these were not available in time. One looks forward to a continuation of this debate.

Of any such work there are bound to be minor criticisms. For example, even Manton momentarily forgets that branchiopod crustaceans do not have calcified cuticles, and that certain attributes of calanoid copepods are not shared by cyclopoids. Such minor points are, however, overshadowed by the labelling problems already mentioned which mar what, irrespective of one's views on its phylogenetic conclusions, must be hailed as one of the most significant works on arthropods ever published.

Geoffrey Fryer

Geoffrey Fryer is a Senior Principal Scientific Officer at the Windermere Laboratory of the Freshwater Biological Association, Ambleside, Cumbria, UK.

\section{Soil \\ classification handbook}

Quantitative and Numerical Methods in Soil Classification and Survey. By R. Webster. Pp. 269. (Oxford University Press: Oxford, New York and London, 1977.) $£ 12.50$.

Although the use of numerical and quantitative methods of data analysis have been a feature of the biological sciences for many years, until recently they have been little used in the mapping or classification of soils. There have been several reasons for this, not the least being the absence of a suitable handbook giving guidance not only with the design of information gathering procedures which would yield data amenable to numerical analysis, but also with the techniques of analysis most suited to such data. With the publication of this excellent book Dr Webster, one of the leading experts on numerical methods in soil science, has provided in one volume just such guidance.

Within the book the author has commendably achieved a balance between the need for statistical theory and the need for the text to be intelligible to the non- mathematical soil scientist. The text takes the reader through a number of introductory chapters covering data handling, problems of measurement and description, sampling and estimation, generalisation and nested classification. From there the author moves on to consider the more sophisticated techniques of multivariate analysis involving ordination and classification, with a final chapter on mapping techniques. Each procedure is discussed in detail, with valuable comments on its applications and limitations. Discussion is further enhanced by the inclusion of worked examples of field data. These examples are invaluable in aiding the comprehension of some of the more complex mutlivariate methods where the text at times is too concise. Even in some of the examples (at least to the uninitiated) figures are apparently derived from nowhere; one such example is the calculation of latent vectors; here the inclusion of the solution to a quadratic would have been of immense value.

These minor criticisms apart, this book should be essential reading for all those seeking guidance in the application of quantitative methods in soil classification and survey.

M. J. Alexander

M. J. Alexander is Lecturer in Geography at the University of Durham. UK.

\section{Encyclopaedia of the platyrrhines}

Living New World Monkeys (Platyrrhini), with an Introduction to Primates. Vol. 1. By P. Hershkovitz. Pp. 1117. (University of Chicago Press: Chicago and London, 1977.) $\$ 80 ; £ 55$.

ThE separation between the New World monkeys (platyrrhines) and the Old World monkeys and apes (catarrhines) is an ancient one. The two groups diverged from pre-simian stock sometime between the end of the Cretaceous and the Eocene, and their living representatives show a wide variety of morphological and physiological differences. Partly because they are less closely related to man and partly because of the limited data available on South American species, the platyrrhines have attracted less attention than the catarrhines, and their taxonomy has long been in serious disarray. This is particularly true of the Callitrichidae (marmosets and tamarins), the smaller and more primitive of the two main existing families of platyrrhines. Hershkovitz's enormous monograph provides an authoritative summary of available knowledge of the morphology, biology and phylogeny of the fourteen existing callitrichid species as well as of Callimico (Goeldi's monkey), which he assigns to the monospecific family, Callimiconidae. The review of the literature is encyclopaedic and particular attention is paid to areas (including comparative physiology, behaviour and ecology) often ignored by comparative anatomists. For many years, this will certainly remain the most important reference work on callitrichids.

Modern evolutionary biologists are likely to be disturbed by Hershkovitz's emphasis on irreversible evolutionary trends in colouration. The coats of 'primitive' species are usually agouticoloured-an effect produced by alternating bands of blackish brown and reddish colour on the terminal half of each hair. Subsequent evolution, Hershkovitz argues, progresses through all-reddish or all-blackish forms and follows "an orderly and irreversible sequence of degeneration that ends in loss of pigment or white" (p94). Mostly white or blackand-white colouring is typical of "advanced" species and of those occurring furthest from the origin of the group. The theory is difficult to accept-both because there is no firm functional reason for predicting that evolution should take this course and because the evidence (apart from colouration) on which species or races are classified as "primitive" or "advanced" is difficult to interpret in the virtual absence of a fossil record. Nevertheless, it is clear that clinal colour variation is not closely related to obvious environmental parameters: not only do 